\title{
Críticas e possibilidades da educação e da escola na contemporaneidade: lições de Theodor Adorno para o currículo*
}

Criticism and possibilities of education and school in the present: lessons of Theodor Adorno for the curriculum

Rita Amelia Teixeira Vilela**

\section{Resumo}

O texto apresenta a dimensão sociológica do pensamento de Theodor Adorno e a sua análise crítica dirigida à escola e ao sistema de ensino, destacando sua atualidade. Retoma-se, também, a discussão sobre a educação para a "emancipação", segundo o teórico, procurando demonstrar que o desafio apontado por ele, para que a Educação possa ser capaz de criar a base para a construção de uma sociedade livre da barbárie, continua atual. Transportada para os desafios que se colocam para a Educação, no atual cenário do neoliberalismo globalizado e de suas contradições, a apropriação do potencial da epistemologia de Adorno torna-se fundamental ao debate da relação entre a escola e a sociedade no mundo contemporâneo, evidenciando como o seu pensamento reforça posturas que, na contemporaneidade, tributam à escola um papel importante na construção de novas relações pedagógicas, orientadas para a produção de novas formas de cidadania, visando construir um mundo no qual se possa viver com justiça e dignidade.

Palavras-Chave: Theodor Adorno; Educação na Contemporaneidade; Currículo

\footnotetext{
Este texto é uma versão modificada da comunicação "Theodor Adorno: críticas e possibilidades da educação e da escola na contemporaneidade", apresentada no Congresso Internacional: "A Indústria Cultural Hoje”, realizado em setembro de 2006, na UNIMEP, em Piracicaba, SP. Incorpora passagens da discussão, gerada por ocasião de outra comunicação, apresentada no III Colóquio luso-brasileiro sobre questões curriculares, realizado em Braga, Portugal, em fevereiro de 2006 (VILELA, Rita Amélia; PERDIGÃO, Denise; MATIAS, Virginia C. B. de Queiroz. Para fazer diferente: possibilidades de currículo emancipatório em Theodor Adorno). As reflexões desenvolvidas em todos os textos são decorrentes da pesquisa intitulada: A teoria crítica da educação de Adorno e sua apropriação para análise das questões atuais sobre currículo e práticas escolares.

** Professora de Sociologia da Educação e pesquisadora da linha de pesquisa Currículo: Políticas e Práticas, no Programa de Pós-Graduação em Educação da Puc-Minas - Mestrado (Belo Horizonte/Brasil). rivilela@uol.com.br.
} 


\section{Abstract}

The text presents the sociological dimension of the thought of Theodor Adorno and his critical analyses pointed to the school and to the educational system, highlighting how it is up-to-date. It also comes back to the discussion of Adorno about education for the emancipation and it shows that the challenge pointed by him for the education to be capable of creating the foundations for the construction of a society free from barbarism continues to be present. Transferred to the challenges that lay ahead for education, in the present scenery of the global new liberalism and its contradictions, the appropriation of the potential of the epistemology of Adorno becomes fundamental in the debate about the relation between the school and the society in the contemporary world, showing how his knowledge reinforces postures that, in the present, demand from the school an important role in the construction of new pedagogical relations for the production of new forms of citizenship looking to construct a world in which it is possible to live with justice and dignity.

Keywords: Theodor Adorno; Education in the Present; Curriculum

\section{INTRODUÇÃO}

No atual momento histórico, a reflexão sobre que tipo de homem estaria afinado com a nova sociedade apresenta questões cruciais para a Educação, para o papel da escola e para os professores. É inegável que existe consenso de que a principal tarefa da escola é desenvolver nos alunos a capacidade de pensar e de tomar decisões, o que significa ir muito além do reprodutor de formas e de conhecimentos preestabelecidos e de pensamentos lineares, frutos de currículos escolares fechados que, sob a força do pensamento cartesiano dominante, predominaram nas escolas dos séculos XIX e XX.

Estudos e debates na área da Educação têm assinalado os desafios da escola diante das contradições da sociedade atual, na qual se evidenciam avanços científicos e tecnológicos numa velocidade nunca antes presente, coabitando com velhas questões ainda não resolvidas: miséria social, fome, conflitos bélicos justificados por razões variadas e nem sempre aceitáveis, esgotamento dos recursos naturais e degradação cada vez maior e sem controle do meio ambiente. A crítica mais pertinente que se pode apontar para os sistemas de ensino da atualidade é que "não respondem às contradições e às demandas provocadas pelos processos de globalização econômica e de mundialização da cultura" (Moreira; Candau, 2003, p. 156). 
O grande desafio hoje, para as escolas e os educadores, está em ter que superar as dificuldades impostas ao sistema escolar, que, além de enfrentar as dificuldades produzidas na nova ordem mundial, é, também, um novo palco de lutas e de contradições decorrentes da democracia de acesso. Esta, ao haver legimado o direito de todos à Educação, levou para a escola grupos sociais e culturais antes ausentes desse espaço, assumindo um caráter inevitavelmente multicultural (Moreira, 2001; Moreira; Candau, 2003; Santos, 2001). Para a escola, isso implica ter que reconhecer o caráter multicultural das sociedades contemporâneas e, portanto, aceitar que é sua responsabilidade saber enfrentar as contradições e as demandas provocadas por essa nova configuração.

Como é possível discutir um projeto de Educação que forme os cidadãos com competências e atitudes necessárias a esse contexto e que responda a questões concretas da sociedade globalizada, neoliberal e multicultural? Como pode Theodor Adorno estar presente nesse debate?

Adorno não é um teórico da Educação, mas nas suas reflexões de ordem filosófico-social, que oferecem formulações fundamentais para o entendimento do homem na sociedade, ou seja, dos processos de (de)formação do homem na sociedade do seu tempo, podemos buscar um arcabouço substancial de análise para a Educação. A discussão da Educação, apresentada como análise e reflexão dialética sobre o desenvolvimento e a decadência da cultura e da educação na sociedade, assume, de forma particular, relevância na sua obra (Horkheimer; Adorno, 2003; Adorno, 1967, 1969, 1979). Alguns de seus escritos assinalam a coerência epistemológica da Teoria Crítica no desvendamento do processo histórico de produção da Educação como relação social de dominação e, ao mesmo tempo, apontam a dimensão de uma tarefa de emancipação social a ser desenvolvida pela escola. Ele pontua essa discussão nos textos que compõem a obra organizada por Kadelbach, em 1970, que tem sido considerada como sendo os escritos do teórico sobre Educação. ${ }^{1}$

Como poderemos, então, dialogar com ele para tentar responder à tensão presente entre as demandas para a Educação e as condições da sociedade nas suas atuais dimensões? É possível desenvolver um diálogo entre Adorno e alguns dos elementos presentes na tensão existente entre as aspirações e os desafios que se colocam para a escola de hoje?

1 Kadelbach (1970a). 
Em primeiro lugar, exploraremos a análise sociológica, dirigida por Adorno à escola e ao sistema de ensino, destacando-se sua atualidade. Em segundo lugar, retomaremos a discussão da Educação para a "emancipação", ${ }^{2}$ atribuída a Adorno, na tentativa de demonstrar que seu desafio para que esta possa ser capaz de criar as bases para a construção de uma sociedade livre da barbárie continua atual, frente aos desafios que se colocam para ela nesse cenário de neoliberalismo globalizado e suas contradições. Com essa discussão, tentaremos demonstrar a apropriação do potencial da epistemologia de Adorno no debate acerca de questões da relação entre a escola e a sociedade no mundo contemporâneo e no enfrentamento dos desafios e impasses para um projeto de Educação que seja formador do homem. Um projeto que abranja a possibilidade de alunos dominarem o conhecimento acumulado que é patrimônio da humanidade, mas que abarque a construção de identidades sociais comprometidas com a justiça social e a convivência solidária.

Adorno prenuncia concepções, hoje, largamente divulgadas: a defesa de um outro conhecimento que considere a cultura de todos os grupos sociais e que seja orientado para uma vida decente no planeta, como postula Santos $(1989,2001)$, e o desencadeamento de uma política curricular que vise a produzir mais igualdade no conjunto global das relações sociais às quais o sistema educacional está vinculado, como defendem Connell (1992, 1995), Moreira (2001), Moreira e Candau (2003), Silva (1998, 2000), Veiga-Neto (2001, 2003, 2004).

As questões colocadas por Adorno quanto ao sistema escolar dos anos 1950/1960 revelam o pioneirismo do seu pensamento ao abordar as relações de poder presentes na escola, na sua organização e nas suas práticas, questão que é central nas teorias curriculares críticas, desenvolvidas posteriormente na Nova Sociologia da Educação ${ }^{3}$ e que,

2 Manterei entre aspas o termo "emancipação", quando me referir à tradução do termo alemão usado por Adorno, Mündigkeit, conforme o que se tornou usual em português, para enfatizar que o vocábulo português não expressa o sentido dado por Adorno. Considero necessária a revisão dessa nomenclatura, ou ainda, mais prudente seria manter o vocábulo alemão, devido à dificuldade para encontrar uma palavra com os múltiplos sentidos colocados por Adorno ao escolher o termo.

3 A Nova Sociologia da Educação: a terminologia NSE, convencionalmente, aplica-se para a situação particular das mudanças na Sociologia da Educação, ocorridas na Inglaterra, no final dos anos 1960 e início dos 1970. No contexto dos estudos sociológicos de situações e processos característicos da vida escolar, surgiram contribuições críticas da escola que modelaram uma sociologia crítica do currículo e das práticas escolares. Para esta, o conhecimento escolar não é neutro, ele carrega ralações de poder (Moreira, 1990; Forquin, 1996; Apple, 1982). 
ainda, sustentam o debate no campo do currículo (Moreira; Silva, 1995; Moreira, 1990; Young, 1971). Desvendar as relações de poder é precondição para operar currículos e práticas escolares, buscando fazer uma outra Educação. A complexidade da questão entre currículo e relações de poder implica que educadores sejam levados a tomar consciência e a entender as conexões entre o que se passa na sala de aula (entre o que se ensina e as relações interpares ali estabelecidas) e o que é produzido fora da escola, isto é, com as relações de poder da sociedade que são mais amplas, desiguais e estruturais. Essa tomada de consciência por parte dos educadores é exigência de uma proposta de Educação que se oriente por criar as possibilidades de uma sociedade emancipada da opressão e da injustiça, tal como postulada por Theodor Adorno.

\section{Theodor Adorno e a análise sociológica dirigida à escola e aO SISTEMA de ENSINO: A SUA ATUALIDADE}

Alguns estudiosos de Theodor Adorno têm reforçado a dimensão sociológica presente em sua obra (Bolte, 1995; Duarte, 2002, 2003; Gruschka, 1988, 1995, 2004; Negt, 1995; Pätzold, 1995; Schiller, 1995; Schweppenhäuser, 2003). Segundo Oskar Negt (1995), o próprio Adorno se declarava, ao mesmo tempo, filósofo e sociólogo, e foram suas reflexões filosóficas que deram fundamentação às suas análises sociais e sustentaram os motivos de suas pesquisas empíricas. Para Gehard Schweppenhäuser (2003), Adorno era filósofo fazendo Sociologia e era sociólogo fazendo Filosofia. Como destaca Negt, para Adorno,

Sociologia é, no sentido mais profundo, a ciência da experiência humana. Portanto, ela implica uma reflexão teórica, dialética, profunda e sutil entre a "gênese" do fenômeno analisado e a sua "validade concreta ou empírica", isto é, como ela é reconhecida. Essa dialética não está separada da forma e do sentido da experiência, como as pessoas viveram e como a apreenderam. A gênese e a validade do fenômeno são uma coisa só. (Negt, 1995, p. 21)

De acordo com Negt, o conceito de Sociologia, formulado por Adorno, coloca duas condições para o desvendamento e a análise da realidade social. A primeira diz que os conceitos a serem formulados, em decorrência dessa análise, abarcam a totalidade da sociedade, pois é através dela que os fenômenos particulares estudados são constituídos. A análise do particular permite reconhecer, sempre, essa totalidade concreta. A outra 
condição, presente no debate de Adorno como sendo a relação do sujeito com o mundo, é o reconhecimento "de que a verdade, buscada pela investigação, depende do esclarecimento da possibilidade incessante de mudança naquilo que foi desvelado" (Negt, 1995, p. 16).

Portanto, a presença da dialética entre o geral e o particular, entre o profundo e o superficial, entre o concreto e o subjetivo, entre o real e outra possibilidade, define, para a Sociologia, segundo Adorno, as condições para o entendimento da realidade. Em cada fenômeno social e em cada relação social, é preciso desvendar esse campo de tensão entre o que aparenta e sua gênese, entre o revelado e a possibilidade imanente de sua mudança. Isso torna a Sociologia de Adorno um meio de reconhecimento e de apreensão do que é verdadeiro no aparente. Além disso, a operação de análise sociológica é processo com sentido: tem a finalidade de desvendar a realidade na sua essência, a gênese e o valor, como condição para devolver ao homem a possibilidade de recuperar a essência da vida humana desprezada e anulada pelas relações de dominação capitalista. A recuperação dessa essência da vida humana seria, para Adorno, uma condição para uma vida correta e justa. Nessa perspectiva, fica evidente a inter-relação entre a perspectiva sociológica e a perspectiva filosófica no pensamento adorniano, e fica demonstrado que sua teoria sociológica é uma ciência social engajada, crítica, marxista, interdisciplinar e tolerante.

Os cientistas sociais que buscam apropriar-se da epistemologia de Theodor Adorno, para desvendar as questões educacionais atuais, reiteram que o entendimento sobre o que Adorno pensa sobre Educação tem que ser buscado na sua Sociologia e na sua Filosofia, porque, na sua obra, essas duas dimensões estão presentes como uma unidade (Gruschka, 1988, 1995, 2004).

Para evidenciar que há uma Sociologia e uma Sociologia da Educação em Adorno, ater-nos-emos, inicialmente, à "Introdução" e a dois dos capítulos da obra clássica (a Dialética do esclarecimento, escrita por ele e por seu parceiro Horkheimer), para nos apropriarmos das possibilidades já presentes de crítica à educação e à escola (Horkheimer; Adorno, 2003). ${ }^{4}$

4 A obra teve sua primeira edição mimeografada, em 1944, no Instituto para a Pesquisa Social, ainda nos Estados Unidos da América, com o título Fragmentos Filosóficos. Em 1947, foi editada em Amsterdã pela Editora QUERIDO e, em 1969, em Frankfurt pela 
Estudiosos dessa obra assinalam que ela teve como finalidade, essencialmente, apresentar uma análise do processo civilizatório (Duarte, 2002; Schweppenhäuser, 1995, 2003). Portanto, os temas tratados são sociológicos. Acrescente-se que a metodologia é uma reflexão hermenêutica histórico-social que demarca a tradição de rompimento dos cientistas sociais da Escola de Frankfurt com a reflexão filosófica sobre problemas sociais e inaugura uma Sociologia com distanciamento da abordagem positivista (Adorno et al., 1973).

Pode-se destacar, como a principal característica da obra - Dialética do esclarecimento -, que ela se apresenta como uma Filosofia Social para entender a história social do homem. No prefácio, os autores anunciam que não conseguiram ater-se aos elementos das ciências tradicionais (a psicologia, a sociologia e a história da ciência), embora tenha sido essa a intenção primeira do próprio projeto, porque elas se mostraram insuficientes e limitadas. A obra revela uma nova concepção de teoria: esta deve ser comprometida com um juízo social-existencial e pretende desenvolver uma reflexão sobre as condições civilizatórias, segundo a interpretação hermenêutica e a recusa do positivismo. Como desafio, eles pretenderam apreender o conceito de esclarecimento, a partir do seu significado como tempo histórico-social, mas, também, e de forma essencial, como dimensão da vida da sociedade burguesa industrial. Essa possibilidade foi oferecida pela peculiaridade do vocábulo alemão Aufklärung (do verbo aufkaeren / auf + klaeren, que significa "esclarecer"), bem como pelos seus usos na linguagem culta e na do povo.

Aufklärung designa o tempo histórico conhecido como Época das Luzes ou Iluminismo, momento histórico-social acontecido entre os séculos XVII e XVIII, quando pôde ser demonstrada a hegemonia do saber sobre as crenças infundidas pela religião e pela ignorância coletiva. É o momento da hegemonia das ciências e das evidências do progresso da civilização, como no processo assinalado por Weber como "desencantamento do mundo" (Weber, 1982). Na linguagem comum e coloquial, Aufklärung significa, mais uma vez, o oposto à ignorância. Designa o processo pelo qual as pessoas se libertam do estado de não saber, pelo qual se livram dos preconceitos e passam a lidar com a racionalidade. É resultante da

Editora Fischer. A Editora Suhrkamp, de Frankfurt, editou a obra, pela primeira vez, em 1981, e, depois, houve uma seqüência de reedições. A obra consultada é da edição de 2003, comemorativa do centenário de Adorno. A tradução brasileira de Guido Antonio de Almeida é da versão editada pela Editora Fischer, em 1969. 
instrução e da educação escolar e sociocultural, através da leitura, que produz a capacidade de reflexão crítica e o entendimento racional do mundo. Assim, no alemão, ein aufgeklärtes Mensch é um homem instruído/ esclarecido, não mais possuído pela ignorância. Não quer dizer que seja emancipado e esclarecido no sentido a ser pleiteado por Adorno.

No primeiro capítulo, destinado a apresentar o conceito de esclarecimento, os autores assumem que seria preciso entender o mundo esclarecido ou "desencantado", na perspectiva assinalada por Weber. Esse entendimento demandava o diálogo com o conceito kantiano, pois, para Kant (1974), esclarecimento é o processo de emancipação intelectual, resultado não apenas do processo histórico de superação da ignorância e da preguiça de pensar por conta própria, mas, também, da capacidade de superar a dominação de uma classe de opressores sobre a humanidade: dominação intelectual, política e econômica. Assim, para Kant, autonomia ou emancipação seria a capacidade de superar a menoridade da razão, ou seja, sua subordinação ao estabelecido e ao aparente e, como conseqüência, a libertação da opressão imposta pelos governantes. Ainda nesse primeiro capítulo, os autores procuram demonstrar o entrelaçamento da racionalidade e da realidade social, o entrelaçamento inseparável entre a racionalidade para dominar a natureza e os resultados contraditórios desse processo, procurando esclarecer como o próprio domínio da natureza tornou-se nova forma de dominação do homem.

No capítulo "A indústria cultural - o esclarecimento como a mistificação das massas", encontram-se uma análise e uma reflexão dialética sobre o desenvolvimento e a decadência da cultura e da educação na sociedade, desvelando o processo de alienação, conseqüente do processo de dominação cultural operado pelos aparelhos produtores e reprodutores da cultura de massa. Nesse texto, os autores desenvolveram a análise das relações sociais sob a heurística dialética marxiana. Assim, evidenciaram o reconhecimento da ambigüidade, constante na realidade em mutação e na apreensão do que significa a sociedade capitalista. Quem é o homem na sociedade concreta, como operam as determinações de ordem econômica (relações de produção) e como o homem pode agir na cultura da sociedade capitalista? Denunciaram, ainda, a tendência da sociedade capitalista de subjugar o indivíduo na torrente da homogeneização, em que prevalece o mecanismo de produzir a heteronomia, ou seja, a condição de ser e de se manter igual ao todo ou ao padronizado; daí decorrem a perda e a destruição do processo de individuação. Como a sociedade 
capitalista prioriza a adaptação ao coletivo, pela adesão no lugar da percepção e da ação autônomas, o resultado é a perda da consciência individual que é substituída pela massificação. Com evidências empíricas, tomadas na produção cultural da sociedade daquele tempo, Horkheimer e Adorno evidenciaram como a cultura de massa e os mecanismos da Indústria Cultural acabam produzindo a regressão do esclarecimento à condição de mera ideologia.

A educação formal não escapou dessa análise. $\mathrm{Na}$ "Introdução" da Dialética do esclarecimento, os autores expressam uma crítica direta à Educação ao situarem o sistema de ensino como uma das instâncias envolvidas com a destruição do verdadeiro esclarecimento, com a destruição da capacidade criativa e da autonomia dos sujeitos: "Tornar inteiramente supérfluas suas funções parece ser, apesar de todas as reformas benéficas, a ambição do sistema educacional" (Horkheimer; Adorno, 2003, p. 13). Essa acusação é reiterada no capítulo destinado a precisarem o conceito de esclarecimento, quando eles apontam os efeitos nefastos de uma educação que elimina a capacidade de reflexão; de uma educação que, além de se identificar com a Indústria Cultural, opera na sala de aula apenas com a lógica positivista, fazendo prevalecer o acúmulo de informações e validando como ciência apenas operações quantificáveis e previsíveis matematicamente. Desse processo é que resultam, segundo os dois teóricos, mentes instruídas mas não esclarecidas.

$\mathrm{Na}$ crença de que a escola deve abarcar apenas e restritamente a constatação de fatos e a aplicação de fórmulas de cálculos, para se proteger a mente da superstição e do charlatanismo, prepara-se o terreno para prevalecer a superstição e o charlatanismo. [...] Na sala de aula, a expulsão do pensamento ratifica a coisificação do homem que já foi operada na fábrica e no escritório. (Horkheimer; Adorno, 2003, p. 47)

Assim, eles sinalizam como a Educação não realiza os ideais iluministas de libertar o homem da opressão, mas, ao contrário, se torna mecanismo que aliena e reproduz a dominação.

Theodor Adorno desenvolveu a crítica à Educação de forma mais direta no texto posterior, "Teoria da semiformação", 5 no qual deu

50 texto de Adorno recebeu, em diversas publicações em português, diferentes denominações para o termo Halbbildung: Semicultura, Pseudoeducação e Semiformação. Minha escolha é pelo termo Semiformação. Meus motivos estão explicitados na nota 12 de uma publicação anterior (Vilela, 2005). 
continuidade à análise e à reflexão dialética sobre o desenvolvimento e a decadência da cultura e da educação na sociedade. Portanto, essa dimensão assume, de forma particular, relevância na sua obra e assinala a coerência epistemológica da Teoria Crítica no desvendamento do processo histórico de produção da educação como relação social de dominação. Isso permite concluir que, nesse texto, encontra-se uma análise sociológica da Educação correspondente à melhor tradição da Sociologia da Educação.

Ao desenvolver a análise dos mecanismos de atuação da Indústria Cultural na sociedade, repercutindo na formação da mentalidade e na ação dos sujeitos, Adorno denuncia que há um processo real na sociedade capitalista que produz o alheamento do homem das suas condições reais de vida social. Nele, está a chave para entender a crítica adorniana, dirigida à Educação: a crise da Educação é a crise da formação cultural da sociedade capitalista, uma formação na qual o homem é alienado, mesmo que tenha sido educado (escolarizado/instruído). A denúncia de Adorno de que a Educação vigente, àquela época, constituía-se numa semiformação, na medida em que, na sociedade industrial capitalista, o indivíduo foi destruído, prevalecendo a massa, o coletivo, a nãoparticularidade, a opressão da identidade autônoma, tem implicações na discussão atual, em que as questões, relacionadas com práticas democráticas e inclusivas, no contexto multicultural e globalizado, se tornaram centrais. Adorno reforça essa dimensão da sua crítica à escola e ao sistema de ensino em textos pontuais, produzidos como palestras ou resultados de debates ${ }^{6}$ e, de forma particular, no texto que empresta a Kadelbach o título: "Erziehung zur Mündigkeit", traduzido no Brasil como "Educação para a emancipação".7

O indivíduo de Adorno, sob o império da Indústria Cultural, que é permanente sob as novas roupagens resultante da ideologia da sociedade,

$6 \quad$ “Fersehen und Bildung” (escrito em 1963); “Erziehung-wozu?" (escrito em 1966), “Erziehung zur Entbarbarisierung” (escrito em 1968); “Erziehung nach Auschwitz” (palestra radiofônica na rádio estatal de Hessem, em abril de 1966, e publicada em 1967). Tradução brasileira: Educação para a emancipação. Petrópolis: Vozes, 1995.

7 Entretanto, esse não é um texto dissertativo, escrito por Adorno sobre Educação. Trata-se de uma discussão desenvolvida, a pedido da rádio estatal de Hessen, entre Adorno e outro educador, Hellmut Becker, que na época era diretor do Instituto para a Pesquisa Educacional da Fundação Max Planck de Berlim, gravada em julho de 1969, um pouco antes da sua morte, ocorrida em 6 de agosto. Foi levada ao ar pela Rádio Estatal de Hessen, em 13 de agosto de 1969. A intenção do editor foi compilar uma produção dispersa do teórico, presente em debates e conferências, considerada expressiva de sua polêmica com questões da Educação da sociedade alemã (Kadelbach, 1970a). 
influenciada pelo avanço das novas tecnologias da informação, perdeu o que há de essencial no humano - a capacidade de subjetivação, de solidariedade, de respeito; perdeu a dignidade. Para nosso teórico, foi essa alienação que tornou possíveis o nazismo, o holocausto e os campos de concentração, porque ela fabrica sujeitos alienados, incapazes de uma relação subjetiva e crítica com sua realidade, ela aumenta o potencial de adesão sem consciência. Assim, se reproduz na vida social o aparente como válido, o falso como verdadeiro (Adorno, 1970a, 1970b).

Ao discutir a "semiformação" sob o império da Indústria Cultural, Adorno explicita sua análise sociológica do sistema de ensino. Ao enfatizar o avanço da "semiformação", ocupando todos os espaços educativos da sociedade, ele deslinda a ideologia do sistema de ensino e denuncia graves problemas pedagógicos. Segundo ele, o aumento das oportunidades educacionais não resultou em melhor formação para o povo, pois, ao ter sido agraciado com o direito à escola, a ele foi dada a impressão de tratamento de igualdade. Entretanto, o que ocorre na Educação incorreta (a semiformação) que recebe é a deformação da sua consciência. Para Adorno, "tudo aquilo que possibilitaria uma reflexão sobre a vida social é descartado no processo educacional" (Adorno, 1979, p. 119).

$\mathrm{Na}$ epistemologia de Adorno, encontramos, também, argumentação para negar a semiformação como algo estabelecido, sem esperanças de superação. Mesmo quando, na avaliação do teórico, a possibilidade de realização do Homem está completamente limitada e condicionada pelo alastramento da semiformação, sob o controle da Indústria Cultural, ele admite e aspira a uma transformação das relações sociais através do processo educativo. No texto dedicado à análise da Indústria Cultural e da semiformação, ele aponta que a Educação deve ser uma arma de resistência contra a força dessa indústria, na medida em que permita o desenvolvimento da consciência crítica e reflexiva, capaz de permitir aos indivíduos desvendarem as contradições da vida social e se capacitarem para o exercício de resistência da cultura verdadeiramente humana, contra a cultura banalizada da e pela Indústria Cultural. Ele reitera essa postura nos textos pontuais sobre Educação: "Educação só faria sentido como promotora das condições para a auto-reflexão crítica" (Adorno, 1970e, p. 90).

Concordando com Zuin (2002), Oliveira (2002) e com Zuin, Pucci e Oliveira (2000), os escritos de Adorno não podem estar ausentes para aqueles que perseguem a recuperação da autocrítica e da reflexão na prática 
educativa e que defendem uma escola que possa cumprir a promessa de uma vida mais justa. Os ensinamentos de Adorno, sobre os processos da Indústria Cultural, continuam atuais e oferecem um potencial teórico indispensável para orientar pesquisas e reflexões que objetivem desvelar e criticar as condições sociais que reiterem, na atualidade, a universalização da semiformação e suas conseqüências na alienação do sujeito, e, de forma particular, como a escola opera esse processo.

Frente ao quadro social da contemporaneidade, torna-se cada vez mais necessário o empenho para a construção de uma concepção educacional crítica que possa orientar práticas educativas de resistência a "esse processo de debilitação da individualidade que é um aspecto gerador da intolerância e do autoritarismo" (Zuin, 2002, p. 10).

Os ensinamentos de Adorno reforçam as posturas no campo da Educação que perseguem a produção de uma nova prática pedagógica, pautada pela "justiça curricular". Essa, de acordo com Connell (1992, 1995), deve ter como princípios: ver e entender os interesses dos menos favorecidos e criar experiências para que esses interesses tenham lugar na escola, não para que as diferenças sejam apenas toleradas, mas para que sejam de fato reconhecidas como direito; que todos tenham direito a uma escolarização comum e de igual qualidade e significado social; que a escola tenha como meta o direcionamento das suas ações para a construção da eqüidade social. As questões educacionais, destacadas por ele, são dimensões bastante atuais, pois ele reivindicou, nos anos 1950-1960, que a Educação fosse um instrumento capaz de criar as bases para a construção de uma sociedade mais justa e mais humana.

Isso nos remete à necessidade de retomar, também, a propriedade do entendimento de Adorno sobre a educação e sobre a escola, que assume uma dimensão de Educação para a resistência ao estabelecido, para demolir o processo social de adesão conformista à ordem social considerada inadequada, uma Educação para autonomia, não para dominação.

\section{Educação para a "Emancipação" segundo Theodor Adorno}

Adorno não tem uma obra na qual desenvolva uma concepção de Educação e, muito menos, uma teoria de educação (como usualmente tem sido atribuída a ele como sendo uma educação para a "emancipação"). Ele também não discute o conceito de emancipação com finalidade pedagógica. A indicação da necessidade de libertação do sujeito do processo 
de dominação da consciência, operada pelos mecanismos da Indústria Cultural, é a referência principal para se entender a posição de Adorno a respeito da Educação e do sistema de ensino do seu tempo.

Como já referido, a obra que traz o título Erziehung zur Mündigkeit, na tradução brasileira Educação para a emancipação, não é um projeto do teórico. Pode-se afirmar que o editor pretendeu reunir textos pontuais que oferecessem aos estudiosos da Teoria Crítica aspectos do debate, ou melhor, do embate empreendido por Theodor Adorno com questões diretamente relacionadas à função do sistema educacional e da escola (Adorno, 1970a, 1970b, 1970c, 1970d, 1970e). Mas essa não é uma obra com finalidade de situar uma teoria da educação adorniana. Os textos editados apresentam, sim, elementos essenciais para se entender a propriedade da teoria social, construída por Theodor Adorno para entender a escola no contexto da sociedade capitalista e para se perceber o compromisso do teórico com a construção de uma outra sociedade, processo no qual caberia à Educação uma tarefa social importante. Entretanto, não se pode depreender, dos textos arrolados na obra, uma proposta de Educação para a "emancipação" como um projeto de ação pedagógica. ${ }^{8}$

Não se pode afirmar nada mais além de que, nesses textos, estaria revelada a defesa do teórico para que a escola trabalhe, como opção pedagógica e política, para favorecer o desenvolvimento da humanização do homem, de modo a capacitá-lo para a auto-reflexão e para ser capaz de agir sobre as condições de opressão, posicionando-se contra elas e libertando-se delas, posição que o autor revela através de um diálogo, de fato pontual, com o tema "Educação" e com os educadores.

Para entender o Theodor Adorno desse conjunto de textos, parecenos fundamental esclarecer o termo alemão, utilizado por ele, para indicar

8 A tradução brasileira desse livro, ao não ter destacado o editor da coletânea como autor do livro, mas atribuindo a Adorno a autoria do mesmo e não, apenas, dos textos nele editados, tem induzido ao equívoco acima referido, situando Adorno como o signatário de uma obra com o título de Educação para a emancipação (o que equivale a ser signatário de uma proposta de Educação para a Emancipação). Isso não é, entretanto, culpa do tradutor, que esclareceu devidamente o contexto da obra e da teoria social revelada por Adorno para tratar temas da Educação (Leo Maar, 1995). Mesmo assim, a obra tem sido referida em publicações brasileiras como: ADORNO, Theodor. Educação para a emancipação. Petrópolis: Vozes, 1995. O correto, entretanto, seria: KADELBACH, Gerd. (Org.). Theodor Adorno: educação para a emancipação. Trad. Wolfgang Leo Maar. Petrópolis: Vozes, 1995. (Original alemão de 1970). 
seu pensamento sobre a escola e a Educação, pois o vocábulo português "emancipação" não revela o sentido pleno tomado pelo teórico. Ao escolher a palavra, Adorno procurou, com ela, revelar a essência do seu pensamento: a educação e o processo social de dominação apresentam uma mesma raiz. Mund significa "boca". Mündigkeit significa a capacidade de falar pela própria boca, falar por si mesmo; mas, para essa condição, o sujeito precisa ser capaz de pensar por si mesmo. Entretanto, o processo social de dominação retirou do homem a capacidade de pensar por conta própria, retirou dele a capacidade de autonomia das suas ações, de falar e de agir por si mesmo. Esse processo social tornou o homem "tutelado", no sentido também tomado de uma outra palavra alemã, de mesma raiz: Mündel é o sujeito que precisa de tutela, é um indivíduo sem capacidade de autonomia, ele precisa de alguém para conduzi-lo. Assim, a Educação para a Mündigkeit, pensada por Adorno, seria a Educação para promover a capacidade do sujeito para libertar-se dessa condição de tutela, para tornálo Mündig; e isso Adorno deixa claro no primeiro parágrafo do texto ao qual dá esse título, referindo-se a Kant:

A exigência de "Muendigkeit" parece óbvia numa democracia. Para deixar isso claro, eu gostaria de referir-me ao início de um pequeno ensaio de Kant que traz o seguinte título: "Resposta à pergunta; $\mathrm{O}$ que é esclarecimento". Neste ensaio, ele define o que seria a menoridade ou necessidade de tutela e, com isso, define, também, o que seria a "Muendigkeit", ao afirmar que não se pode culpar o homem desse estado de menoridade porque ele não resulta da falta de entendimento e de conhecimento, mas, sim, da sua predisposição e de sua falta de coragem, o que determina que suas ações precisem ser guiadas por outrem. Assim, esclarecimento é a libertação do homem da sua menoridade, do seu estado de tutela. (Adorno, 1970c, p. 133) ${ }^{9}$

Nessa evidente identificação com Kant (1974), para Adorno, esclarecimento é a capacidade de, sem medo, poder ser diferente. Pressupõe a coragem e a aptidão de cada um em se servir de seu próprio esclarecimento, de dispensar ou superar seu estado de tutela.

Assim, queremos deixar evidente que o que procuramos discutir é, em parte, a interpretação dada por estudiosos de Adorno sobre uma

9 Mantenho o vocábulo Mündigkeit, em alemão, para enfatizar a dificuldade ou mesmo impropriedade para tradução do termo. O trecho traduzido, acima, procura revelar o sentido da colocação de Adorno e não é uma tradução literal, porque esta modificaria o sentido explicitado por ele. 
concepção de Educação que seja capaz de se contrapor aos processos sociais estabelecidos de dominação. Uma Educação que se oriente pela necessidade de formar sujeitos capazes de falar e agir por si próprios; o que implica, como condição, serem capazes de pensar com autonomia. E isso tem implicações pedagógicas para a atualidade.

Uma Educação para a Mündigkeit, ou dirigida para a autonomia, tal como pensada por Adorno, seria capaz de fazer o homem descobrir sua força de ação para a mudança, para construir o seu verdadeiro mundo de justiça social sob a égide da tolerância, da solidariedade, do respeito e da ação coletiva, orientada para o bem comum. Deliberadamente, deve fomentar a capacidade de superar o conformismo e a indiferença, a capacidade de experimentar, de arriscar, de fazer diferente dos outros, de romper com a heteronomia resultante da vida social sob as relações sociais capitalistas. Heteronomia que se revela na vida social, pautada por ações determinadas fora do sujeito, e, assim, torna as pessoas dependentes de normas que não são assumidas pela sua própria razão.

É preciso entender que a direção de uma Educação para a Mündigkeit, de acordo com Adorno, buscaria promover o desenvolvimento da subjetividade e da individualidade como condição para viver a pluralidade da vida social humana, uma vez que ele aponta como princípio de libertação das relações sociais danificadas a capacidade máxima de cada um se constituir como sujeito. Para Adorno, quem não é autônomo não tem condições de reconhecer a autonomia do outro; portanto, quem não se enxerga como o sujeito não tem condições de aceitar o outro como sujeito. Nesse sentido, a Educação, para superar o estado de dominação da consciência, deveria ser um programa deliberado de resistência ao estabelecido, para formar sujeitos não tutelados, autônomos, capazes de pensar, de falar e de agir por si mesmos, capazes de enfrentar a contradição imanente na vida social sob o capitalismo e agir contra essa condição. Ele assinala, também, que toda ação pedagógica deveria enfrentar, em teoria e prática, a dialética entre a aparência do mundo e sua realidade; deveria buscar a compreensão da realidade, não da sua aparência, entender o que ela é; deveria superar o determinismo de ter que viver a aparência; deveria refletir causa e conseqüência de todas as relações sociais e buscar outras formas de pensar e de agir, para além das formas dominantes de adesão e de adaptação, pautadas na lógica da Indústria Cultural. O resultado dessa nova orientação pedagógica seria formar uma outra consciência, oposta àquela dominante na sociedade alienada. No lugar da adaptação e do 
adestramento, a ação escolar deveria desenvolver a autonomia e a capacidade de resistência à dominação.

Segundo Kadelbach, ao prefaciar o livro que editou com os textos de Adorno sobre Educação, é preciso entender que, mais do que um conceito, Educação para a Mündigkeit seria a forma como ele, Adorno, se posicionava como sujeito e como cientista social diante de questões educacionais do seu tempo (Kadelbach, 1970b). Coerente com sua filiação à Teoria Crítica, Adorno teria revelado, nesses textos, seu posicionamento a favor de uma tarefa da escola, orientada para a formação de sujeitos com capacidade de autonomia de pensamento e de ação. E essa era sua opção política.

Entender o que Adorno via no sistema de ensino daquele tempo não é apenas ver sua crítica a uma instituição que propagava os mecanismos de dominação na sociedade capitalista; mas, também, compreender a visão do autor, sustentada pela perspectiva sociológica de seu pensamento, que avaliava a escola como sendo a instituição social ainda capaz de formar o homem libertado das amarras da dominação inerentes à ordem social capitalista.

Nesse sentido, para quem deseja entender como Adorno se posiciona sobre a Educação, sobre a escola e o sistema de ensino, torna-se necessário retomar seus escritos elucidativos sobre a propagação dos processos sociais de dominação do pensamento, que constituem, em essência, sua análise sociológica da sociedade. É do conjunto da obra de Adorno que se pode deduzir como ele defende (como condição primordial para a realização de uma outra Educação, contrária àquela que produz sujeitos tutelados, no sentido kantiano) uma Educação dirigida a fomentar o desenvolvimento deliberado da capacidade de superar o conformismo e a indiferença, da capacidade de experimentar, de arriscar, de perder o medo de agir por conta própria, para ser e fazer diferente do que está estabelecido: "A única força efetiva contra o princípio de Auschwitz seria autonomia, se eu posso aplicar a expressão de Kant: o poder da reflexão, para a capacidade de se conduzir por si próprio, para a não adesão.” (Adorno, 1970e, p. 93)

\section{Possibilidades da educação e da escola na CONTEMPORANEIDADE}

Parece ser inegável a pertinência das contribuições de Adorno para orientar uma análise sociológica crítica e engajada da nossa escola, no 
mundo de hoje; o que tem implicações particulares no debate e na implementação de políticas e práticas curriculares, cuja centralidade está na defesa de uma escola democrática, assentada numa perspectiva de inclusão da pluralidade cultural na sociedade. Nessa dimensão, a escola inclusiva deve ser o universo de igualdade, de respeito e de trocas mútuas. Da mesma forma, demanda-se uma perspectiva ampliada de formação escolar, incorporando-se perspectivas de Educação para a humanização do homem, que foram relegadas pela hegemonia de aspectos de formação intelectual e cientificista nas propostas educacionais, desenvolvidas nos séculos XIX e XX.

Isso representa, na prática pedagógica, nas concepções e desenvolvimento de políticas curriculares, a construção de uma Educação que, em primeiro lugar, abandone sua dimensão de unilateralidade de visão de mundo e de conhecimento. Em segundo lugar, que se assuma na escola seu sentido político, pautando uma proposta pedagógica que combine o compromisso de uma avaliação ética e moral da sociedade contemporânea com uma atitude concreta de ação política contra as incongruências da vida social: um mundo globalizado e multicultural, uma sociedade cada vez mais sofrida em conseqüência do neoliberalismo e com indivíduos cada vez mais submetidos à lógica do mercado.

Assim, as contribuições de Adorno parecem ser adequadas para amparar ações pedagógicas que almejem: realizar uma escolarização bemsucedida; formular currículos que contemplem as diferenças socioculturais; reconsiderar o sentido das diferenças, para que estas não se convertam em desigualdades e injustiças. As reflexões acerca do papel da escola, tendo como base o que Adorno pensou e defendeu para a Educação, podem auxiliar a conduzir a ação pedagógica na perspectiva de uma política curricular, assentada no compromisso com empreendimentos, voltados para a construção de saberes que combinem a formação humana e o reconhecimento das diferenças, como condição para uma vida social pautada pelo princípio da inclusão.

Para Gruschka (2004), atualmente um dos cientistas sociais alemães que discute e pesquisa a Educação alemã de acordo com o referencial da Teoria Crítica, o debate atual sobre o sentido e o papel da escola tem, na análise social fornecida por Adorno, uma estrutura de referência, não apenas para a crítica, mas, sobretudo, para a reorientação da organização e das práticas pedagógicas. Assumindo a posição desse autor, tentamos 
arrolar sinteticamente algumas lições, ${ }^{10}$ tomadas em Adorno, que consideramos serem apropriadas para se pensar um projeto pedagógico contemporâneo, lições que sinalizam algumas condições necessárias para orientar o desenvolvimento de uma outra Educação, que se oriente para o desenvolvimento de sujeitos com autonomia de pensamento e de ação. São elas:

1) As formas dominantes de pensar na sociedade e espelhadas na escola são conseqüências da estrutura da sociedade capitalista e se sustentam:

- na cisão entre trabalho intelectual e manual e na hierarquia social dela decorrente;

- na cisão entre pensar e sentir: o homem perdeu as capacidades de afetividade e de sensibilidade;

- na Indústria Cultural, como agência de formação cultural legitimada na sociedade: deforma a formação humana e, assim, elimina o esclarecimento;

- no sujeito social heterônomo: ele é igual aos outros, ele é massa e não indivíduo, ele é sem subjetividade e sem autonomia;

- em uma escola que está conformada à dimensão de uma sociedade em que reina a desigualdade e a opressão.

2) É preciso desmistificar as aparências da escola que promete a libertação e a realização do homem, mas mantém e reproduz os mecanismos propulsores da opressão. Nessa escola:

- há hierarquia entre aquelas destinadas aos talentosos e as destinadas aos não-talentosos: isso corresponde à organização curricular, pautada na hierarquia das disciplinas e a escolas diferentes para grupos sociais diferentes. Os resultados dessa organização hierarquizada são a seletividade e a exclusão social;

10 Não quero dizer, com isso, que as lições são de Adorno, ou seja, apresentadas por ele para a Educação. O vocábulo "lição" aponta dois sentidos: pode referir-se à matéria ou tema ensinado por alguém (o professor/um teórico); pode referir-se àquilo que foi apreendido ou assimilado por alguém (aluno/cidadão). As lições arroladas acima são minhas, no sentido que as deduzi do debate com dimensões da obra adorniana, das suas lições sobre a vida social no mundo danificado, mas, também, da sua crença na possibilidade de uma outra sociedade e da tarefa da Educação na sua construção. Assumo, portanto, que qualquer aproximação com uma perspectiva mais normativa para a escola e para os professores é resultado da minha posição de educadora. 
- almeja-se socializar os sujeitos, pautando-se na perspectiva de adaptação ao status quo, uma vez que ela adestra para a competência e para a competição no lugar de desenvolver a reflexão, o entendimento, a subjetividade e a autonomia.

3) Comprometer-se com a Educação para a autonomia não é fazer ativismo pedagógico para conscientizar pessoas, como acontece através de muitos programas escolares que anunciam como objetivo formar o cidadão politicamente engajado e crítico. Educar para a autonomia, coerente com a dimensão apontada por Adorno, implica uma nova postura para os educadores que deveriam reconhecer que:

- não se forma consciência autônoma sem a vivência do projeto dirigido à autonomia;

- abraçar a causa da educação para a autonomia sem a devida reflexão teórica, ou seja, sem entender as raízes históricas da alienação, continua sendo alienação;

- é preciso compreender, primeiro, como se produziu a semiformação;

- projetos pedagógicos ou curriculares de educação para a autonomia correm os riscos de não ultrapassarem a dimensão de serem apenas novas idéias de Educação, convertendo seus meios em seus próprios fins;

- a reflexão e o entendimento na vivência da autonomia é que podem definir um novo modelo de Educação.

4) Um novo modelo de educação/proposta curricular para os desafios da vida social na atualidade deveria levar em conta que:

- compreender a realidade social é compreender-se nessa realidade;

- é preciso educar para a resistência ao estabelecido, para negar e superar a seletividade e a exclusão;

- é preciso construir a autonomia no lugar da heteronomia: os alunos devem aprender a agir, não por adesão ao dominante, mas por decisão particular, fundada no entendimento, na reflexão, na compreensão e na capacidade de serem conseqüentes com suas escolhas e decisões;

- os sujeitos sociais precisam aprender a serem indivíduos e não a se conduzirem como horda nas suas relações sociais; é essencial que percam o medo de serem diferentes, eles precisam desenvolver a autonomia para pensar e para agir. 
5) O debate acerca da alteridade e da diferença, essencial para se poder efetivar a educação inclusiva, que, hoje, é demanda central nos projetos e práticas educacionais, deve considerar como princípio básico que essa Educação não se efetive sem a plenitude de desenvolvimento do processo de subjetivação e individualização; pois, para Adorno, subjetividade e individualidade são aspectos centrais para se abarcar, na experiência educacional, todas as pessoas, independentes de seu pertencimento a grupos de classe social, de gênero, de etnias e outras singularidades. Esses dois elementos são ingredientes substanciais para o desenvolvimento de relações de respeito e de tolerância. Adorno deixa claro que quem não é autônomo não pode reconhecer a autonomia do outro. Para enxergar o "outro" como sujeito é essencial o próprio desenvolvimento como sujeito.

6) A escola não pode continuar sendo uma caixa fechada hermeticamente às questões sociais da atualidade. O discurso pedagógico incorpora as imagens e as mensagens da nova sociedade, mas a organização escolar e as ações pedagógicas continuam (re)produzindo as velhas dimensões porque:

- tomam a Educação como privativa da escola e, por isso, insistem em que o problema está em ter que "competir" com outras instâncias da sociedade que teriam assumido a função de educar - a TV, as tecnologias da comunicação e da informação, os grupos culturais etc.;

- reforçam a não-autonomia, uma vez que, no cotidiano escolar, prevalecem o fazer pelo fazer, o enfraquecimento da criatividade, a adaptação ao dominante, em nome da harmonia e da ordem, o embotamento das formas de sensibilidade artística e de manifestações de sentimentos. Essa Educação mutila o homem;

- os rituais da escola, os exercícios e os mecanismos de avaliação, pautados pelos princípios de separar, ordenar e excluir, preparam sujeitos para um percurso de vida que nada se difere daquilo que foi a separação das pessoas entre aquelas que mereceriam e que deveriam ser encaminhadas para os campos de concentração.

7) A escola precisa superar sua noção de "emancipação", pois, tal como propagada no discurso de uma Educação para atender a sociedade contemporânea, ela tem uma dimensão técnica - ela 
é traduzida como formação de competências para a eficiência, para a produtividade e para o sucesso econômico. Entretanto, para Adorno:

- a Educação para a concorrência exclui a aprendizagem da cooperação, da tolerância e da solidariedade;

- a escola que se orienta para avaliar o que faz, com base em leituras de estatísticas para poder "operar a seleção" sem receios, ou sem escrúpulos, não forma para a solidariedade e para a cooperação, não forma para a subjetividade e para a autonomia.

8) Mas a escola pode fazer outra Educação, e criticar a escola acarreta o compromisso de transformá-la. Assumir que reconhecia a possibilidade de outra Educação estava, para Adorno, dialeticamente associado à crítica da Educação vigente, à sua incapacidade formativa. Criticar e ver a possibilidade de um outro modo era, de fato, o projeto pessoal de Adorno, ou seu compromisso político para com a Educação. E essa é a essência da sua contribuição.

\section{Conclusão}

As lições, arroladas por nós, pretenderam defender, com Adorno, que é possível uma nova escola. Nesta, deve ser considerado, em primeiro lugar, que todo o processo escolar deve ser dirigido à derrubada das barreiras que limitam as pessoas, que não as deixam tomarem parte, plenamente, na vida social, e as impedem de compartilhar todos os recursos e bens culturais e materiais. Para isso, a escola deve criar condições para que sejam desenvolvidas atitudes de respeito a opiniões e visões de mundo diferentes. Assim, ela deve tomar como princípio: fortalecer cada forma particular de pensar e de agir; despertar a esperança de que cada pessoa, independentemente de suas particularidades (cor, raça, culturas, gênero etc.), tenha reconhecido e legitimado seu direito à vida e à participação na sociedade. E, finalmente, a escola deve desenvolver o espírito de solidariedade e de tolerância como princípio básico, capaz de defender a formação da personalidade. Esse espírito é condição que possibilita a cada sujeito o direito a um lugar na sociedade e que faz com que ele se sinta parte dela.

Queremos insistir na atualidade dessas lições, buscadas em Adorno, no debate da função social da escola na contemporaneidade. Elas revelam 
como seu pensamento faz coro com cientistas sociais contemporâneos que continuam a tributar à escola um papel importante na construção de novas relações pedagógicas, orientadas para a produção de novas formas de cidadania. Seguem apenas alguns indicadores:

A escola tem que ser uma escola de cidadania, cidadania crítica, que deve ensinar e instruir coletivamente para a rebeldia, quando ela se justifique, obviamente, e para o conformismo, quando o conformismo for a concordância com idéias que nós criticamente consideramos como progressistas e nossas, e não porque o são oficialmente ou porque somos objeto de doutrinação. O que é preciso é retirar da escola todo princípio de doutrinação, e ele existe não só na maneira como nós ensinamos, mas, na forma como nós avaliamos. (Santos, 2001, p. 30)

Só através de uma criação sistemática, apurada e metódica do pensamento crítico independente, da cidadania ativa, de uma luta por uma transformação emancipatória paradigmática, se justifica a escola e aí, sim, ela tem toda a legitimidade e deve continuar. (Santos, 2001, p. 31)

Minha preocupação com a escola decorre de considerá-la capaz de promover a crítica do existente e o questionamento do que parece inscrito na natureza das coisas; capaz, então, de formar indivíduos não conformistas, rebeldes, transgressores, comprometidos com a luta contra toda e qualquer opressão. Decorre de considerá-la, em síntese, espaço público em que, em meio a práticas, relações sociais e embates se produzem significados e identidades. Nesse espaço novos tempos podem ser anunciados. (Moreira, 2001, p. 68)

Em alguns processos de trabalho uma sociedade transforma seu ambiente (por exemplo, na manufatura) e, em outros, uma sociedade transforma-se a si mesma. A educação é um exemplo desse segundo tipo. Ela pode ser definida como o trabalho organizado cujo objetivo último é a capacidade para a prática social e cujo meio específico é a capacidade para adquirir estratégias de aprendizagem. (Connel, 1995, p. 25)

[...] quero salientar o papel da escola como a grande instituição envolvida na civilidade, ou seja, envolvida na transformação dos homens: de selvagens em civilizados. A escola como o lugar capaz de arrancar cada um de nós - e assim arrancar a sociedade de que fazemos parte - da menoridade, e nos lançar num estágio de vida mais evoluído, criando uma sociedade formada por cidadãos que 
por estarem na "mesma cidade", estão num ambiente comum e, por isso, têm de aprender a viver minimamente se tolerando, em cooperação mútua e sem se barbarizarem. Esse, talvez, seja o sentido mais radical da escola moderna. (Veiga-Neto, 2003, p. 104)

Esperamos ter deixado evidente o potencial da epistemologia de Adorno no debate acerca de questões da relação entre a escola e a sociedade no mundo contemporâneo. Estivesse Adorno refletindo conosco sobre nossos problemas educacionais da atualidade, estaria ele nos exigindo repensar nossos projetos de democracia escolar e nos convidaria, com certeza, a implementar currículos escolares perseguindo a verdadeira eqüidade. Da mesma forma, ele estaria defendendo práticas pedagógicas; portanto, ações curriculares com perspectivas mais amplas de formação humana e cultural. Não apenas as dimensões particulares, próprias de segmentos culturais presentes na escola, deveriam ser abarcadas, mas, também, dimensões relacionadas com a formação humana multifacetada, como a artística e a espiritual, que são indissociáveis.

Gostaria de poder reafirmar, com Adorno, a potencialidade da Educação para permitir aos indivíduos desvendarem as contradições da vida social e para capacitá-los para um exercício de resistência da cultura verdadeiramente humana contra a barbárie da sociedade danificada: "Essa tarefa não é para ser assumida pela Educação, ela é tarefa da Educação." (Adorno, 1979, p. 120)

Assim, quero defender que a Educação para Mündigkeit, pensada e defendida por ele, tem uma força especial para amparar a escola contemporânea no enfrentamento dos seus desafios. O desvendamento dos mecanismos de dominação e de como são produzidos os processos de segregação, de racismo e de xenofobia, de como eles operam dentro das escolas, de como eles conduzem à banalização dos problemas decorrentes da injustiça social e como continuam a produzir segregação e seleção, apesar da propagação do discurso pró-inclusão, é uma condição necessária para se poder mudar a escola de hoje.

\section{Referências Bibliográficas}

ADORNO, Theodor W. et al. La disputa del positivismo en la sociología alemana. Barcelona/México: Ed. Grijalbo, 1973.

ADORNO, Theodor W. Teorie der Halbildung. In: Soziologische

Schriften I. Frankfurt: Suhrkamp Taschenbuch, 1979. p. 93-121. 
ADORNO, Theodor W. Erziehung - Wozu? In: KADELBACH, Gerd (Hrsg.). Theodor Adorno: Erziehung zur Mündigkeit - Vorträge und Gespräche mit Hellmut Becker: 1959-1969. Frankfurt: Suhrkamp, 1970a.

. Erziehung zur Entbarbarisierung. In: KADELBACH, Gerd (Hrsg.). Theodor Adorno: Erziehung zur Mündigkeit - Vorträge und Gespräche mit Hellmut Becker: 1959-1969. Frankfurt: Suhrkamp, 1970b.

. Erziehung zur Mündigkeit. In: KADELBACH, Gerd (Hrsg.). Theodor Adorno: Erziehung zur Mündigkeit - Vorträge und Gespräche mit Hellmut Becker: 1959-1969. Frankfurt: Suhrkamp, 1970c.

Fernsehen und Bildung. In: KADELBACH, Gerd (Hrsg.). Theodor Adorno: Erziehung zur Mündigkeit - Vorträge und Gespräche mit Hellmut Becker: 1959-1969. Frankfurt: Suhrkamp, 1970d.

. Erziehung nach Ausschwitz. In: KADELBACH, Gerd (Hrsg.). Theodor Adorno: Erziehung zur Mündigkeit - Vorträge und Gespräche mit Hellmut Becker: 1959-1969. Frankfurt: Suhrkamp, 1970e.

. Negative Dialektik. Jargon der Eigentlichkeit. Frankfurt: Suhrkamp, 1969.

. Minima Moralia: Reflexionen aus dem beschädigten Leben. Frankfurt: Suhrkamp, 1967. . Educaşão e emancipação. São Paulo: Paz e Terra, 1995.

. Kulturkritik und Gesellschaft. In: ADORNO, Theodor W. Kulturkritik und Gesellschaft II - Eingriffe Stichvworte. Frankfurt: Suhrkamp Taschenbuch Wissenschaft, 2003.

APPLE, Michael W. Ideologia e curriculo. São Paulo: Brasiliense, 1982.

BOLTE, Gerhard. Von Marx bis Horkheimer. Aspekte Kritischer Theorie im 19 und 20 Jahrbundert. Darmstadt: Wiss Buchgesellschaft/WSG, 1995.

CONNELL, R. W. Política educacional, hegemonia e estratégias de mudança social. Teoria e Educação, n. 5, p. 66-80, 1992.

. Justiça conhecimento e currículo na educação contemporânea. In: SILVA, Luiz Heron da; AZEVEDO, José Clovis de. Reestruturação curricular: teoria e prática no cotidiano da escola. Petrópolis: Vozes, 1995.

DUARTE, Rodrigo. Teoria crítica da Indústria Cultural. Belo Horizonte: Editora UFMG, 2003.

- Adorno e Horkheimer: a Dialética do Esclarecimento. Rio de Janeiro: Zahar, 2002. (Col. Filosofia Passo a Passo).

FORQUIN, Jean-Claude. As abordagens sociológicas do currículo. Educação e Realidade, v. 1, n. 22, p. 187-198, jan./jun. 1996.

GRUSCHKA, Andreas. Kristische Pädagogik nach Adorno. In: GRUSCHKA, Andréas; ÖVERMANN, Ulrich (Hrsg.). Die Lebendigkeit der kritischen Gesellschaftstheorie. Wetzlar: Büchse der Pandora, 2004. 
GRUSCHKA, Andreas. Adornos Relevanz für Pädagogik. In: SCHWEPPENHÄUSER, Gerhard (Hrsg.). Soziologie im Spätkapitalismus: zur Gesellschaftstheorie Theodor W. Adornos. Darmstadt: Wiss Buchgesellschaft/ WBS, 1995.

. Negative Pädagogik. Eiführung in die Pädagogik mit kritischer Theorie. Wetzlar: Büchse der Pandora, 1988.

HORKHEIMER, Max; ADORNO, Theodor W. Dialelektik der Aufklärung. Frankfurt: Suhrkamp, 2003.

Kulturindustrie. Aufklärung als Massenbetrug. In: HORKHEIMER, Max; ADORNO, Theodor W. Dialelektik der Aufklärung. Frankfurt: Suhrkamp, 2003.

KADELBACH, Gerd (Hrsg.). Theodor Adorno: Erziehung zur Mündigkeit Vorträge und Gespräche mit Hellmut Becker: 1959-1969. Frankfurt: Suhrkamp, 1970a.

. Vorwort. In: KADELBACH, Gerd (Hrsg.). Theodor Adorno: Erziehung zur Mündigkeit - Vorträge und Gespräche mit Hellmut Becker: 1959-1969. Frankfurt: Suhrkamp, 1970b.

KANT, Immanuel. Beantwortung der Grage: was ist Aufklärung? Petrópolis: Vozes, 1974.

LEO MAAR, W. À guisa de introdução. Adorno e a experiência formativa. In: ADORNO, T. W. Educaşão e emancipação. São Paulo: Paz e Terra, 1995.

MOREIRA, Antonio Flávio Barbosa. Sociologia do currículo: origens, desenvolvimento e contribuições. Em Aberto, Brasília, n. 46, ano 9, p. 73-84, abr./jun. 1990.

MOREIRA, Antonio Flávio Barbosa; SILVA, Tomaz Tadeu da (Org.). Currículo, cultura e sociedade. São Paulo: Cortez, 1995.

. A recente produção científica sobre o currículo e multiculturalismo no Brasil (1995-2000): avanços, desafios e tensões. Revista Brasileira de Educação, n. 18, p. 65-81, set./out./nov./dez. 2001.

MOREIRA, Antonio Flávio Barbosa; CANDAU, Vera Maria. Educação escolar e cultura(s): construindo caminhos. Revista Brasileira de Educação, n. 23, p. 156-167, mai./jun./jul. 2003.

NEGT, Oscar. Der Soziologe Adorno. In: SCHWEPPENHÄUSER, Gerhard (Hrsg.). Soziologie im Spätkapitalismus: zur Gesellschaftstheorie Theodor W. Adornos. Darmstadt: Wiss Buchgesellschaft/WBS, 1995.

PÄTZOLD, Heinz. Kultur und Gesellschaft bei Adorno. In: SCHWEPPENHÄUSER, Gerhard (Hrsg.). Soziologie im Spätkapitalismus: zur Gesellschaftstheorie Theodor W. Adornos. Darmstadt: Wiss Buchgesellschaft/ WBS, 1995. 
OLIVEIRA, Newton Ramos de. O ato de ensinar numa sociedade administrada. Cadernos CEDES, n. 54, p. 19-27, 2002.

SANTOS, B. de Sousa. Introdução a uma ciência pós-moderna. Rio de Janeiro: Graal, 1989.

- Dilemas do nosso tempo: globalização, multiculturalismo e conhecimento. Educação \& Realidade, v. 26, n. 1, p. 13-32, jan./jul. 2001.

SCHILLER, Hans-Ernst. Übertreibung: Philosophie und Gesellschaft bei Adorno. In: SCHWEPPENHÄUSER, Gerhard (Hrsg.). Soziologie im Spätkapitalismus: zur Gesellschaftstheorie Theodor W. Adornos. Darmstadt: Wiss Buchgesellschaft/ WBS, 1995.

Theodor W. Adorno - zur Einführung. Hamburg: Justus Verlag, 2003.

SCHWEPPENHÄUSER, Hermann. Kunst-Geschichte-Gesellschaft. In: SCHWEPPENHÄUSER, Gerhard (Hrsg.). Soziologie im Spätkapitalismus: zur Gesellschaftstheorie Theodor W. Adornos. Darmstadt: Wiss Buchgesellschaft, 1995. SILVA, Luiz Heron da (Org.). Século XXI. Qual conhecimento? Qual currículo? Petrópolis: Vozes, 2000.

- (Org.). Escola cidadã no contexto da globalização. Petrópolis: Vozes, 1998.

VEIGA-NETO, Alfredo. Currículo e cultura. Um passo adiante. In: MOREIRA, Antonio Flavio; PACHECO, José Augusto; GARCIA, Regina Leite (Org.).Currículo: pensar, sentir, diferir. Rio de Janeiro: DP\&A, 2004.

. Políticas do global e das singularidades. Educação \& Realidade, v. 26, n. 1, p. 13-32, jan./jul. 2001.

- Pensar a escola como uma instituição que pelo menos garanta a manutenção das conquistas fundamentais da Modernidade. In: COSTA, Marisa Vorraber. A Escola tem futuro? Rio de Janeiro: DP\&A, 2003.

VILELA, Rita Amelia T. Para uma Sociologia Crítica da Educação em Adorno e Horkheimer: apontamentos. In: MAFRA, Leila; TURA, Maria de Lourdes R. Sociologia para educadores 2: o debate sociológico no século XX e as perspectivas atuais. Rio de Janeiro: Quartet, 2005.

WEBER, Max. Ensaios de Sociologia. Rio de Janeiro: Guanabara, 1982.

YOUNG, Michael F. D. Knowledge and control. New directions for the sociology of education. London: Collier-Macillan Publishers, 1971.

ZUIN, Antonio A. Soares. Sobre a atualidade do conceito de Indústria Cultural. Cadernos CEDES, n. 54, p. 09-18, 2002.

ZUIN, Antonio A. Soares; PUCCI, Bruno; OLIVEIRA, Newton Ramos de. Adorno. O poder educativo do pensamento crítico. Petrópolis: Vozes, 2000.

Recebido em: 12/09/06

Aprovado em: 11/04/07 